(1)

CrossMark

\title{
Physical activity to improve health: do not forget that the lungs benefit too
}

\author{
Luis Puente-Maestu ${ }^{1,2,3}$ and William W. Stringer ${ }^{4,5}$
}

Affiliations: 'Servicio de Neumología del Hospital Universitario Gregorio Marañón, Madrid, Spain. ${ }^{2}$ Instituto de investigación Sanitaria Gregorio Marañón, Madrid, Spain. ${ }^{3}$ Facultad de Medicina de la Universidad Complutense de Madrid, Madrid. ${ }^{4}$ Harbor-UCLA Medical Center, Los Angeles BioMedical Research Institute at Harbor-UCLA Medical Center, Torrance, CA, USA. ${ }^{5}$ Geffen School of Medicine at UCLA, Los Angeles, CA, USA.

Correspondence: Luis Puente-Maestu, Hospital General Universitario Gregorio Marañón, Servicio de Neumología, c/ Doctor Ezquerdo 46, 28007 Madrid, Spain. E-mail: Ipuente.hgugmasalud.madrid.org

@ERSpublications

Physically active children will enjoy better lung function in adulthood http://ow.ly/P1Pk30hFIPS

Cite this article as: Puente-Maestu L, Stringer WW. Physical activity to improve health: do not forget that the lungs benefit too. Eur Respir J 2018; 51: 1702468 [https://doi.org/10.1183/13993003.02468-2017].

In this issue of the European Respiratory Journal, HANCOX and RASMUSSEN [1], present an analysis of data from two cohorts, one from Denmark and the other from New Zealand, demonstrating that, in cross-sectional analyses at all ages in both cohorts, aerobic fitness during the childhood and adolescence period was positively associated with forced expiratory volume in $1 \mathrm{~s}$ (FEV1) and forced vital capacity (FVC) (figures 1 and 2). This association persisted despite independently adjusting for height, weight, sex, current asthma and current smoking. Each standard deviation difference in fitness was associated with a modestly higher predicted values for FEV1 and FVC (2-3\%).

Their data were derived from analysing the Odense (Denmark) schoolchild and the Dunedin (New Zealand) studies. The Odense cohort is a prospective community-based random cohort of 1369 schoolchildren, first investigated during their third grade (age 8.5-11 years) in 1985. Further spirometry and maximal exercise tests were performed at 9, 15, 21 and 29 years of age. The Dunedin Multidisciplinary Health and Development Study is a population-based cohort of individuals born in Dunedin between April 1972 and March 1973. Peak aerobic fitness was first estimated at the age of 15 years, and then at 26,32 and 38 years old. In this study, peak oxygen uptake was calculated from a submaximal exercise at $70 \%$ of the peak predicted heart rate. In addition to the reciprocal association between exercise capacity and lung function, the study found that the improvements in lung function due to enhanced physical fitness during childhood and adolescence reached early adulthood, i.e. being physically active in the early stages of life was associated with improved adult lung function. The present study demonstrates that these differences could reach up to $0.5 \mathrm{~L}$ for men and $0.36 \mathrm{~L}$ for women in FVC at the age 29 years, and $0.35 \mathrm{~L}$ and $0.21 \mathrm{~L}$ at the age of 38 respectively (contrasted between an individual $2 \mathrm{SD}$ above the average oxygen uptake and another $2 \mathrm{SD}$ below). The results of this study are also in keeping with previous cross-sectional evidence demonstrating a relationship between fitness and lung function in children and adolescents [3,4], and previous tentative longitudinal information such as a nonrandomised intervention study in 7-year-old children, which found that physical training was associated with greater lung volumes over 5 years [5]. The current study also endorses the Amsterdam Growth and Health Study results, in which spirometry and aerobic fitness on a treadmill running test were followed from age 13 to 27 years in 167 individuals. A longitudinal association between fitness and FVC was identified [6];

Received: Nov 282017 | Accepted after revision: Dec 112017

Conflict of interest: Disclosures can be found alongside this article at erj.ersjournals.com

Copyright CERS 2018 

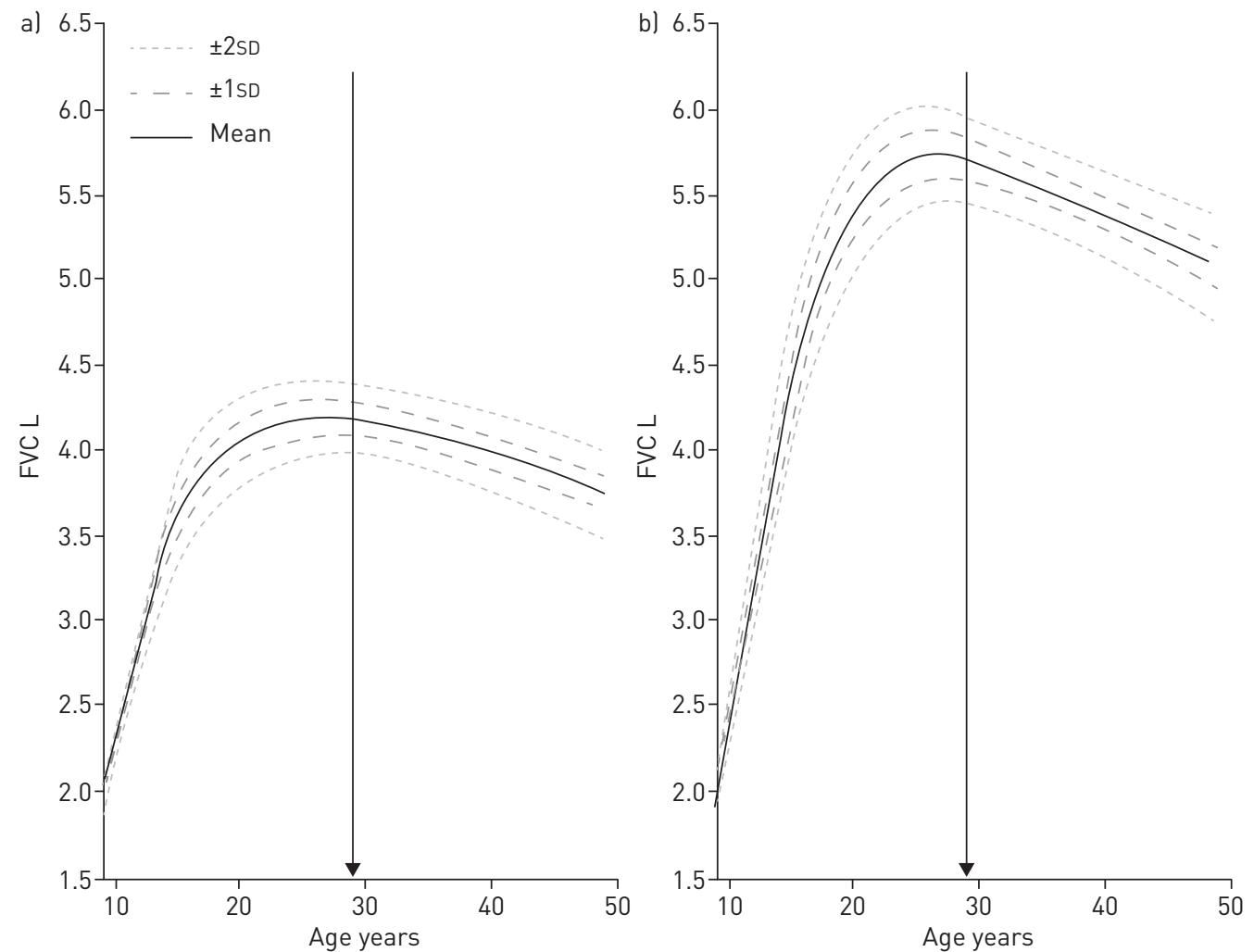

FIGURE 1 Evolution of forced vital capacity (FVC) with age according to level of fitness in the Odense (Denmark) cohort. The graph is created from the cross-sectional values of the Odense cohort. The vertical arrow is the age at which the last Odense cohort data were collected. From that point, the evolution is extrapolated according to BENCK et al. [2]. Mean and SD are those of the oxygen uptake. a) Female. b) Male.

however, contrary to the current study by HANCOX and RASMUSSEN [1], no association with FEV1 was identified statistically in the Amsterdam investigation. Interestingly, cross-sectional studies in adults [7-13] show a similar association between fitness and lung function, even among smokers [7], and longitudinal studies in that population have shown that both young adulthood level of physical fitness on the one hand, and achieving increased fitness from young adulthood to middle age on the other can reduce the "physiologic" decline in both FEV1 and FVC by $5-6 \mathrm{~mL} \cdot \mathrm{year}^{-1}$ [7-11]. Pooling together all this information, a clear message appears to present itself: enhancing fitness in the early years of life improves lung function, and staying active reduces the rate of decline of lung function in both smokers and nonsmokers.

Limitations of the study are that in the Dunedin cohort, peak oxygen uptake was estimated from submaximal exercise (however, these predictions tend to have good accuracy on average [14]) and the retrospective nature of the analyses. Also, neither study extends into older adulthood. A potential association between low physical activity, smoking habits and obesity is excluded in the current study since the relationship persisted after controlling for these variables.

Possible explanations for the association between fitness and lung function might be that the regular and forceful inspiration and expiration for prolonged periods of time during exercise leads to strengthening of the respiratory muscles [15]. Maximum lung inflation and deflation is an important physiological stimulus for the release of surfactant [16], and finally, among the pneumocyte type II population, there appears to be some stem cells with the potential to develop new alveoli, at least in rodents, after the development period [17].

In adults, cardiorespiratory fitness has been shown to be protective against the development of cardiovascular diseases [18], arterial hypertension [19], hyperlipidaemia [20] and type 2 diabetes [21]. While these metabolic and cardiovascular benefits of physical activity are of the utmost importance, we tend to neglect that fitness improves lung health too and to complete the picture, the evidence presented in this paper shows that improving fitness in childhood and adolescence results in better lung function in early adulthood. 

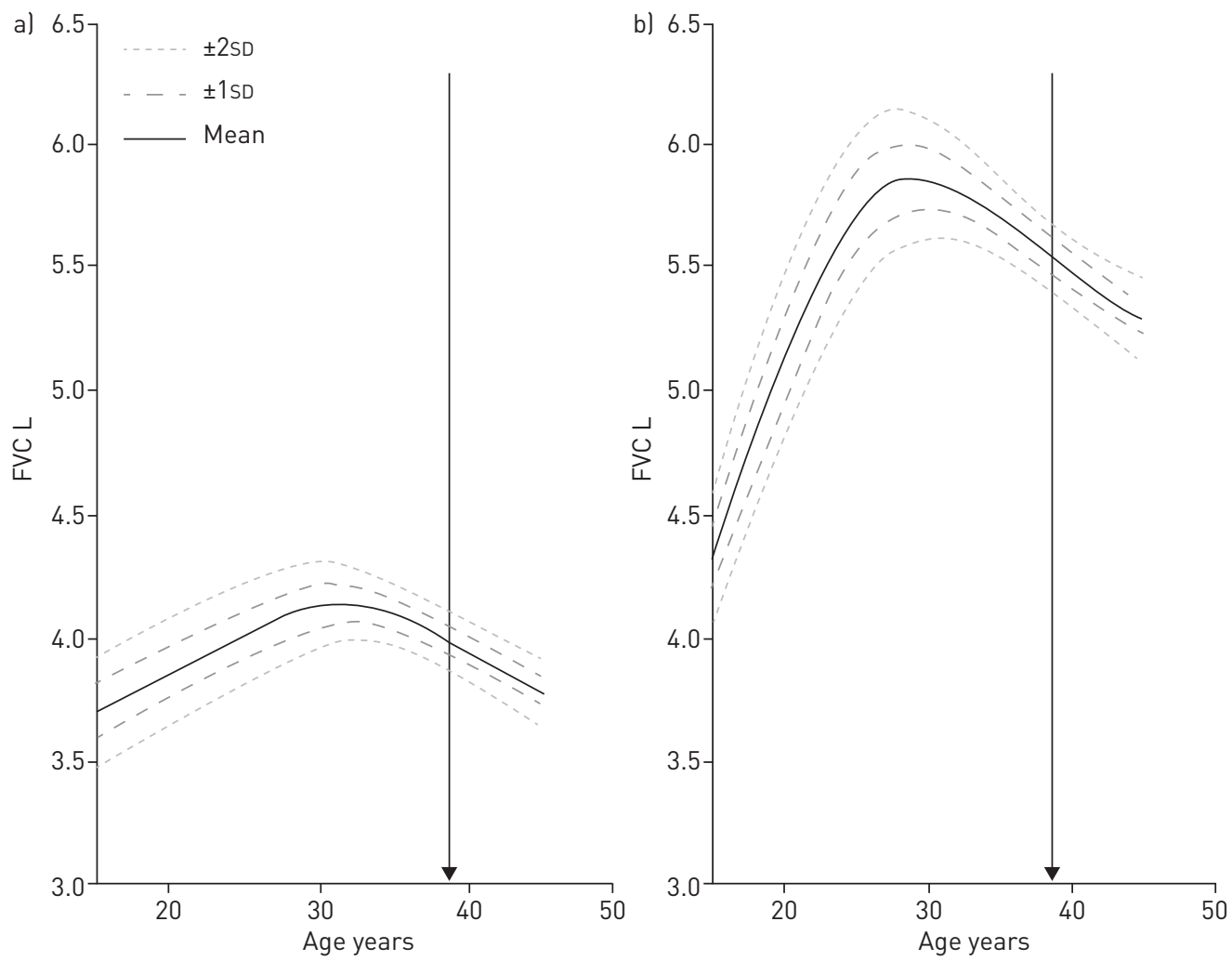

FIGURE 2 Evolution of forced vital capacity (FVC) with age according to level of fitness in the Dunedin (New Zealand) cohort. The graph is created from the cross-sectional values of the Dunedin cohort. The vertical arrow is the age at which the last Dunedin cohort data were collected. From that point, the evolution is extrapolated from Benck et al. [2]. Mean and SD are those of the oxygen uptake. a) Female. b) Male.

Daily active play and physical activity have traditionally been an important part of life for children and adolescents. Today, computers, excessive homework and social media have decreased the need and desire for children to move and play. Participation in physical activity decreases with age and the decline is greater in girls than boys.

Regular physical activity in youngsters induces many desirable physical, physiological and psychological changes [22], and this study shows that among them is improving their current respiratory health and future lung function. An interesting corollary to this work is that physical activity may partially offset the effects of tobacco on the lungs and, while smoking cessation unquestionably should be pursued as the main preventable respiratory health harm, physical activity should be also promoted to improve lung health.

The European Lung Foundation's Healthy Lungs for Life campaign (www.healthylungsforlife.org) seeks to reduce the number of people suffering from lung conditions by raising awareness and knowledge of lung conditions and ways to prevent lung damage. So far, Healthy Lungs for Life's interest has been focused on tobacco and pollution risks for lung health, and promoting physical activity in patients with chronic lung diseases; yet there is a bulk of evidence suggesting that reduced physical fitness, both in youngsters and in adults, results in a poorer lung function. Moreover, the present paper adds a significant contribution in the field by linking increased fitness in teenagers with adult pulmonary function. Thus, promoting fitness at all ages in non-sick populations might well constitute a future theme for a campaign to improve overall lung health.

The challenges associated with getting children active every day should be met with age-appropriate physical activities, enthusiastic leadership, and support from family and friends. While the cut-off points are not clear, a sedentary lifestyle in the childhood and adolescence is recognised as a major risk factor for obesity and cardiovascular disease later in life [22]. Moreover, physical activity during childhood and adolescence is one important factor influencing physical activity during adulthood [22] and we now know, with the information produced by the current study, that physically active children will enjoy a better respiratory life. 


\section{References}

1 Hancox RJ, Rasmussen F. Does physical fitness enhance lung function in children and young adults? Eur Respir J 2018; 51: 1701374 .

2 Benck LR, Cuttica MJ, Colangelo LA, et al. Association between cardiorespiratory fitness and lung health from young adulthood to middle age. Am J Respir Crit Care Med 2017; 195: 1236-1243.

3 Berntsen S, Wisloff T, Nafstad P, et al. Lung function increases with increasing level of physical activity in school children. Pediatr Exerc Sci 2008; 20: 402-410.

4 Menezes AM, Wehrmeister FC, Muniz LC, et al. Physical activity and lung function in adolescents: the 1993 Pelotas (Brazil) birth cohort study. J Adolesc Health 2012; 51: S27-S31.

5 Shephard RJ, Lavallee H. Effects of enhanced physical education on lung volumes of primary school children. J Sports Med Phys Fitness 1996; 36: 186-194.

6 Twisk JW, Staal BJ, Brinkman MN, et al. Tracking of lung function parameters and the longitudinal relationship with lifestyle. Eur Respir J 1998; 12: 627-634.

7 Barboza ML, Barbosa AC, Spina GD, et al. Association between physical activity in daily life and pulmonary function in adult smokers. J Bras Pneumol 2016; 42: 130-135.

8 Cheng YJ, Macera CA, Addy CL, et al. Effects of physical activity on exercise tests and respiratory function. $\mathrm{Br}$ J Sports Med 2003; 37: 521-528.

9 Fuster V, Rebato E, Rosique J, et al. Physical activity related to forced vital capacity and strength performance in a sample of young males and females. Coll Antropol 2008; 32: 53-60.

10 Higgins M, Keller JB, Wagenknecht LE, et al. Pulmonary function and cardiovascular risk factor relationships in black and in white young men and women. The CARDIA Study. Chest 1991; 99: 315-322.

11 Jakes RW, Day NE, Patel B, et al. Physical inactivity is associated with lower forced expiratory volume in 1 second: European Prospective Investigation into Cancer-Norfolk Prospective Population Study. Am J Epidemiol 2002; 156 : 139-147.

12 MacAuley D, McCrum E, Evans A, et al. Physical activity, physical fitness and respiratory function - exercise and respiratory function. Ir J Med Sci 1999; 168: 119-123.

13 Sandvik L, Erikssen G, Thaulow E. Long term effects of smoking on physical fitness and lung function: a longitudinal study of 1393 middle aged Norwegian men for seven years. BMJ 1995; 311: 715-718.

14 Smith AE, Evans H, Parfitt G, et al. Submaximal exercise-based equations to predict maximal oxygen uptake in older adults: a systematic review. Arch Phys Med Rehabil 2016; 97: 1003-1012.

15 Summerhill EM, Angov N, Garber C, et al. Respiratory muscle strength in the physically active elderly. Lung 2007; 185: 315-320.

16 Hildebran JN, Goerke J, Clements JA. Surfactant release in excised rat lung is stimulated by air inflation. J Appl Physiol Respir Environ Exerc Physiol 1981; 51: 905-910.

17 Desai TJ, Brownfield DG, Krasnow MA. Alveolar progenitor and stem cells in lung development, renewal and cancer. Nature 2014; 507: 190-194.

18 Blair SN, Kampert JB, Kohl HW III, et al. Influences of cardiorespiratory fitness and other precursors on cardiovascular disease and all-cause mortality in men and women. JAMA 1996; 276: 205-210.

19 Jae SY, Heffernan KS, Yoon ES, et al. Temporal changes in cardiorespiratory fitness and the incidence of hypertension in initially normotensive subjects. Am J Hum Biol 2012; 24: 763-767.

20 Carnethon MR, Gidding SS, Nehgme R, et al. Cardiorespiratory fitness in young adulthood and the development of cardiovascular disease risk factors. JAMA 2003; 290: 3092-3100.

21 Juraschek SP, Blaha MJ, Blumenthal RS, et al. Cardiorespiratory fitness and incident diabetes: the FIT (Henry Ford ExercIse Testing) project. Diabetes Care 2015; 38: 1075-1081.

22 Hallal PC, Victora CG, Azevedo MR, et al. Adolescent physical activity and health: a systematic review. Sports Med 2006; 36: 1019-1030. 